\title{
Effect of Intact Parathyroid Hormone on Hepatic Glucose Release in the Dog
}

\author{
Keith A. Hruska, Joan Blondin, Raymond Bass, Julio Santiago, Lorraine \\ Thomas, Paul Altsheler, Kevin Martin, and Saulo Klahr, Renal and \\ Metabolism Divisions, Departments of Internal Medicine and Pediatrics, \\ Washington University School of Medicine, St. Louis, Missouri 63110
}

A B S T RACT The liver has been shown to remove parathyroid hormone (PTH) from its arterial circulation by a mechanism that is selective for the intact form of the peptide (PTH 1-84). The present studies demonstrate that PTH has biologic effects on the liver in vivo. Bovine PTH 1-84 stimulated hepatic glucose release in dogs with indwelling hepatic vein catheters from basal values of $31 \pm 8$ to $68 \pm 9 \mathrm{mg} / \mathrm{min}$ per $\mathrm{kg}$ after bolus injections of PTH. The effect on hepatic glucose release was apparent by $5 \mathrm{~min}$ and persisted for the 80 min of observation. The $\mathrm{NH}_{2}$-terminal PTH fragment (syn b-PTH 1-34) had no effect. Bovine PTH 1-84 administered in doses designed to produce circulating levels of immunoreactive PTH similar to the endogenous levels observed in uremic dogs also increased the incorporation of ${ }^{14} \mathrm{C}$ from infused $\left[{ }^{14} \mathrm{C}\right]$ alanine into glucose, and increased estimated hepatic uptake of both chemical and $\left[{ }^{14} \mathrm{C}\right]$ alanine, while increasing hepatic glucose release. Thus, administration of "physiologic levels" of b-PTH 1-84 stimulated hepatic glucose release in part through increased gluconeogenesis in vivo, whereas syn b-PTH 1-34 had no demonstrable effect. Circulating levels of insulin rose after PTH administration, an increase which presumably represents a secondary response to the rise in glucose release.

These results suggest that the liver is a target organ of PTH, and that PTH might potentially alter carbohydrate metabolism during hypersecretion. They also suggest that hepatic uptake of PTH may be related in part to production of a specific biologic effect rather than just simple peptide degradation.

\section{INTRODUCTION}

We have demonstrated (1) that the liver is a major site of uptake for bovine parathyroid hormone (b-PTH $)^{1}$ in the

Received for publication 23 September 1978 and in revised form 11 May 1979.

${ }^{1}$ Abbreviations used in this paper: A - V, arterial minus awake dog. The hepatic uptake mechanism for b-PTH was found to be specific for the intact form of the hormone (PTH 1-84) and no uptake of $\mathrm{COOH}-$ or $\mathrm{NH}_{2}$ terminal fragments could be demonstrated. In addition, no hepatic uptake was demonstrable for biologically active synthetic $\mathrm{NH}_{2}$-terminal tetratricontapeptide (syn b-PTH 1-34). Addition of COOH-terminal fragments to hepatic venous plasma was observed after b-PTH 1-84 injections, indicating degradation of b-PTH 1-84 by the liver after its uptake.

The observation of selective hepatic uptake of b-PTH 1-84 and lack of uptake of PTH fragments including syn b-PTH 1-34 raised the question of whether this difference also applied to the expression of biological effects of PTH on the liver. The liver has not been demonstrated to be a major target organ for PTH in vivo. However, PTH has been shown to markedly stimulate renal gluconeogenesis in vitro $(2,3)$, and to have slight to moderate effects in stimulating hepatic adenylate cyclase, glycogenolysis, and gluconeogenesis in rat liver homogenates and hepatocytes $(4,5)$. In addition, PTH inhibition of glycogen synthesis has been demonstrated in the isolated perfused rat liver (6).

Thus, these studies were designed to investigate possible biological effects of PTH on the liver in vivo and determine if the difference in uptake between b-PTH 1-84 and syn b-PTH 1-34 extended to the expression of biologic activity of the hormone.

\section{METHODS}

Preparation of dogs. Mongrel dogs weighing 18-26 kg were fed a standard high protein Purina dog chow (Ralston Purina Co., St. Louis, Mo.) and had free access to water. Before study during laparotomy, catheters were placed in the left common hepatic vein, as described (1) by the method of Shoe-

venous concentration; $\mathrm{A}-\mathrm{PV}$, arterial minus portal vein glucose concentration; b-PTH, bovine PTH; HV - A, hepatic venous minus arterial glucose concentration; HV - PV hepatic vein minus portal vein glucose concentration; $\mathrm{PTH}$, parathyroid hormone; syn b-PTH 1-34, synthetic $\mathrm{NH}_{2}$-terminal tetracontapeptide. 
maker et al. (7), and the portal vein. Catheter patency was maintained by intermittent filling with heparin. After surgery, the dogs were followed closely for resumption of normal food intake and return of bowel function. The shortest time interval after surgery to study was $48 \mathrm{~h}$. Dogs that were not eating full rations or having normal formed stools were not studied.

Study protocol. Dogs were studied awake and resting in a sling after a 12 -h fast. The femoral artery was catheterized by the Seldinger technique (8) and a polyethylene catheter was advanced into the aorta to the approximate level of the celiac axis. A hind leg vein catheter was placed for infusion of solutions, and injections of PTH.

Hepatic plasma flow was measured by reported methods (1) using constant infusion of indocyanine green (ICG; Hynson, Westcott \& Dunning, Inc., Baltimore, Md.). The hepatic arteriovenous difference for ICG also served as a marker for adequacy of hepatic venous sampling to exclude contamination of samples with inferior vena cava blood (9).

Control aortic, hepatic, and portal vein plasma samples were obtained at 60,30 , and 10 min before injection of PTH preparations. After injections of $2.5 \mu \mathrm{g} / \mathrm{kg}$ b-PTH 1-84, 2.5 $\mu \mathrm{g} / \mathrm{kg}$ syn b-PTH 1-34 or an equal volume of vehicle used in reconstituting $\mathrm{PTH}$, blood samples were obtained from the three catheters simultaneously every 5-20 min for up to 100 min after injection. All blood samples were collected in heparinized tubes and centrifuged immediately. The plasma was separated into aliquots, and stored at $-40^{\circ} \mathrm{C}$. In those tubes for glucagon and insulin determinations, Trasylol (100 $\mu$ l; FBA Pharmaceuticals, Inc., New York) was present as a preservative in each test tube. Glucose and ICG were determined immediately after centrifugation.

Studies with isotope infusions. These studies were conducted as described above except that an infusion of $\left[\mathrm{U}-{ }^{14} \mathrm{C}\right]-$ alanine (New England Nuclear, Boston, Mass.) $0.15 \mu \mathrm{Ci} / \mathrm{kg}$ per $\mathrm{h}$ was begun after a priming dose of $0.1 \mu \mathrm{Ci} / \mathrm{kg}$ and continued throughout the study. $120 \mathrm{~min}$ of isotope infusion was allowed for equilibration before control blood samples were obtained from hepatic vein, portal vein, and aortic catheters at 120, 140, 160 , and 180 min of infusion. After control bloods were obtained, a b-PTH 1-84 infusion ( $12-15 \mathrm{ng} / \mathrm{kg}$ ) was begun. The PTH infusion was designed to maintain immunoassayable PTH levels of $1 \mathrm{ng} / \mathrm{ml}$. An additional period of $60 \mathrm{~min}$ was allowed for reequilibration of isotope before experimental bloods were drawn from all catheters at 240, 260, 280, and $300 \mathrm{~min}$ of $\left[\mathrm{U}-{ }^{14} \mathrm{C}\right]$ alanine infusion. Blood samples for isotopic counting were transferred immediately to tubes containing an equal volume of perchloric acid $(3 \mathrm{mM})$.

Sources of PTH. b-PTH 1-84 was obtained from Inolex Biomedical Div., Glenwood, Ill. (1,100-1,500 U/mg sp act in the Munson bioassay). Syn b-PTH 1-34 was obtained from Beckman Instruments, Inc., Spinco Div., Palo Alto, Calif. $(3,700 \mathrm{U} / \mathrm{mg}$ sp act in a renal adenylate cyclase system). Both PTH preparations were reconstituted in $0.2 \%$ acetic acid, $\mathrm{pH}$ 3.5 , and added to dog plasma for injection. Biologic activity of all PTH preparations was established by their ability to decrease the tubular reabsorption of phosphorus in the dogs studied and to stimulate $3^{\prime} 5^{\prime}$-cyclic AMP production in isolated canine renal tubules. The methods employed in the incubation of PTH preparations with canine renal tubules have been reported (10). Levels of $3^{\prime} 5^{\prime}$-cyclic AMP were determined by radioimmunoassay according to the method of Steiner et al. as reported (11). ${ }^{125} \mathrm{I}-3^{\prime} 5^{\prime}$-cyclic AMP used as a tracer in the radioimmunoassay was purchased from New England Nuclear.

Chemical determinations. Glucose was determined by the glucose oxidase method with a Beckman glucose analyzer (Beckman Instruments, Inc., Fullerton, Calif.). In samples from the isotopic infusion studies, glucose was determined in a microfluorometric assay as described below. Radioimmunoassays for plasma glucagon and insulin were performed in the Washington University Diabetes Center by reported methods $(12,13)$. Creatinine and phosphorus were determined by reported methods (1).

Isotopic counting. Samples for the determination of $\left[{ }^{14} \mathrm{C}\right]$ alanine were prepared by the method of Garber et al. (14). Blood samples were added to an equal volume of $3 \mathrm{mM}$ perchloric acid and centrifuged. The supernate was neutralized with a potassium hydroxide-imidazole mixture and then added to a $1 \times 4-\mathrm{cm}$ column of Dowex AG-X8 (Dow Corning Co. Midland, Mich.) to remove lactate. The column eluate was placed on a second column of Dowex AG-50-X8 and the initial eluate No. 1 was collected. The columns were then treated with $3 \mathrm{~N}$ ammonium hydroxide and a second eluate collected. Eluate No. 1 was lyophilized to dryness, reconstituted, and measured for total glucose content. Eluate No. 2 was lyophilized, reconstituted with $0.02 \mathrm{~N}$ sodium citrate ( $\mathrm{pH} 3.5$ ) and placed on a $1 \times 20$-cm column of HPB80 and eluted with $0.2 \mathrm{~N}$ sodium citrate. The alanine eluate was lyophilized, reconstituted and counted for ${ }^{14} \mathrm{C}$ radioactivity and total alanine was assayed with a fluorometric assay (15). Glucose was determined using a microfluorometric assay (16) in eluate No. 1 from the Dowex AG-50-X8 column. Alanine recoveries ranged from 82 to $98 \%$. Radioisotope counting was performed in a refrigerated liquid scintillation spectrophotometer (Searle Analytic, Inc., Des Plaines, Ill.).

Calculations. Hepatic plasma flow (HPF) was calculated by dividing the metabolic clearance rate of ICG (infusion rate in micrograms per minute divided by arterial ICG micrograms per milliliter) by the hepatic arterial minus venous concentration (A - V) difference for ICG. Glucose addition to the hepatic venous blood was calculated as the product of the hepatic venous minus arterial glucose concentration (HV - A) difference and the HPF. Because there was a small arterialportal $\mathrm{A}-\mathrm{V}$ difference at all times, the calculated hepatic glucose production rates as performed represent an underestimate. Because electromagnetic flow probe methodology for direct determination of hepatic arterial and portal venous blood flow was not available, hepatic alanine uptake was calculated as the product of an estimate of alanine delivery to the liver and the hepatic extraction of alanine. Alanine delivery was estimated as the product of 2 (portal alanine) plus arterial alanine $/ 3$ and the $\mathrm{HPF}$, because the delivery from portal venous blood accounts for $\cong$ two-thirds of delivery in basal conditions (17). After PTH injections, alanine delivery was estimated as the product of portal alanine plus arterial alanine/ 2 and the HPF, because PTH increases the percentage of hepatic blood flow from the systemic circulation to $\cong 50 \%$ (17). Hepatic alanine extraction was calculated by the formula, estimated alanine delivery concentration minus hepatic vein alanine/estimated alanine delivery concentration. The estimated alanine delivery concentration was calculated as above in base-line periods and after PTH injections. These calculations again take into account the sources of hepatic blood flow and the effects of PTH on portal venous and hepatic arterial blood flow (17). The use of the calculations that took into account redistribution of hepatic blood supply after PTH did not significantly affect the results of estimated alanine uptake compared to calculations that employed only the mean of the portal and arterial alanine concentrations, without redistribution of blood flow, as the alanine delivered.

\section{RESULTS}

The hepatic handling of ICG by the dogs used in these studies is shown in Table I along with the mean 
TABLE I

Hepatic Handling of ICG in Studies with b-PTH 1-84 and syn b-PTH 1-34

\begin{tabular}{|c|c|c|c|}
\hline \multirow[b]{2}{*}{ Dog } & \multirow{2}{*}{$\begin{array}{c}A-V \\
\text { difference } \\
\text { ICG }\end{array}$} & \multicolumn{2}{|c|}{ HPF } \\
\hline & & $\begin{array}{c}\text { Mean } \\
\text { base-line }\end{array}$ & Post PTH \\
\hline & $\%$ & \multicolumn{2}{|c|}{$\mathrm{ml} / \mathrm{min} / \mathrm{kg}$} \\
\hline \multicolumn{4}{|c|}{ b-PTH $1-84$} \\
\hline 1 & 13 & 24.3 & 23.7 \\
\hline 2 & 22 & 17 & 13 \\
\hline 3 & 10 & 24.2 & 26.2 \\
\hline 4 & 16 & 28.6 & 33.7 \\
\hline 5 & 21 & 21.2 & 21.2 \\
\hline 6 & 15 & 26.8 & 25.2 \\
\hline 7 & 12 & 25.4 & 24.5 \\
\hline 8 & 13 & 29.5 & 33 \\
\hline$\overline{\mathrm{m}}$ & 15.3 & 24.6 & 25.1 \\
\hline SEM & \pm 1.5 & \pm 1.4 & \pm 2.3 \\
\hline$P$ & & \multicolumn{2}{|c|}{ NS } \\
\hline \multicolumn{4}{|c|}{ syn b-PTH 1-34 } \\
\hline 1 & 16 & 27.7 & 28.1 \\
\hline 2 & 10 & 36.5 & 39.7 \\
\hline 3 & 10 & 31.1 & 31.1 \\
\hline 4 & 14 & 25.2 & 25.2 \\
\hline 5 & 16 & 27.4 & 28.6 \\
\hline 6 & 11 & 20.0 & 20.0 \\
\hline 7 & 11 & 20.9 & 21.0 \\
\hline$\overline{\mathrm{m}}$ & 12.6 & 26.9 & 27.7 \\
\hline SEM & \pm 1.02 & \pm 2.2 & \pm 2.5 \\
\hline$P$ & & \multicolumn{2}{|c|}{$\begin{array}{l} \pm 2.2 \text { NS } \\
\end{array}$} \\
\hline
\end{tabular}

$\overline{\mathrm{m}}=$ mean.

calculated HPF before PTH injections (base-line periods) and after (post-PTH periods) PTH. Each HPF value is the mean of three to four determinations for base-line periods and six to eight determinations for post-PTH periods. The arterial-hepatic vein ICG concentration difference ranged from 10 to $22 \%$, and there was no significant difference in the hepatic handling of ICG (ICG A - V difference) after injections of (b-PTH 1-84) or (syn b-PTH 1-34) compared to control periods. Likewise, the calculated HPF did not differ between the two groups of dogs. Average mean $\mathrm{HPF}$ in the base-line periods was $24.6 \mathrm{ml} / \mathrm{min}$ per $\mathrm{kg}$ in dogs given b-PTH $1-84$ and $26.9 \mathrm{ml} / \mathrm{min}$ per $\mathrm{kg}$ in dogs given syn b-PTH 1-34. Neither b-PTH 1-84 nor syn bPTH 1-34 had a significant effect on HPF.

In the protocol used in these studies, hepatic venous, portal venous, and arterial plasma samples were obtained from awake fasting dogs with indwelling vessel catheters at intervals before and after the injection of PTH. To examine the spontaneous changes of glucose with time, sham experiments were conducted in three dogs. During sham experiments, the $0.02-\mathrm{M}$ acetic acid vehicle used to reconstitute PTH was injected alone. Arterial glucose concentrations fell slightly (5-10 $\mathrm{mg} / \mathrm{dl}$ ) during the $300 \mathrm{~min}$ of observation. The portal venous glucose closely mimicked arterial glucose concentration and demonstrated a small $\mathrm{A}-\mathrm{V}$ difference (A - PV) 0-4 mg/dl in each dog studied. The HV - A difference did not change by more than $2-3 \mathrm{mg} / \mathrm{dl}$ after injections of the vehicle alone.

The effects of bolus injection of b-PTH 1-84 (2.5 $\mu \mathrm{g} / \mathrm{kg})$ and syn b-PTH $1-34(2.5 \mu \mathrm{g} / \mathrm{kg})$ on glucose concentrations in the hepatic vein are shown in Table II. b-PTH 1-84 significantly increased the hepatic vein glucose concentration in each dog studied and increased the mean hepatic vein glucose in this group of dogs from $104 \pm 3 \mathrm{mg} / \mathrm{dl}$ in the base-line periods to $121 \pm 6 \mathrm{mg} / \mathrm{dl} 5 \mathrm{~min}$ after injection. The increase in hepatic vein glucose concentration persisted for up to $80 \mathrm{~min}$ after injection. Mean hepatic vein glucose concentrations at every interval from 5 to 80 min after the injection of b-PTH 1-84 were significantly different from the mean base-line control glucose concentrations. In dogs injected with syn b-PTH $1-34$, the mean base-line glucose concentration of 108 $\mathrm{mg} / \mathrm{dl}$ was not significantly altered by administration of the hormone. Although basal plasma glucose concentrations tended to be slightly higher in the dogs receiving syn b-PTH 1-34 than basal glucose concentrations in the dogs receiving b-PTH $1-84$, these differences were not statistically significant.

Fig. 1A portrays the change in the HV - A glucose concentration difference after PTH injections as compared to the mean $\mathrm{HV}-\mathrm{A}$ of base-line periods. In dogs injected with syn b-PTH 1-34 the HV - A glucose concentration difference after PTH did not vary by more than $2 \mathrm{mg} / \mathrm{dl}$ when compared to the HV - A of the base-line periods. In Fig. IB the change in hepatic vein minus portal vein glucose concentration ( $\mathrm{HV}-\mathrm{PV}$ ) difference is shown. Again, b-PTH 1-84 caused an increase in the $\mathrm{HP}-\mathrm{PV}$ glucose concentration difference similar to the change in $\mathrm{HV}-\mathrm{A}$, whereas injections of syn b-PTH 1-34 failed to change the HV - PV difference by more than $2 \mathrm{mg} / \mathrm{dl}$. In Fig. $1 \mathrm{C}$ the arterial minus portal vein glucose concentration (A - PV) difference is portrayed. The A - PV difference ranged from 0 to $4 \pm 1 \mathrm{mg} / \mathrm{dl}$ and was not significantly altered by either b-PTH 1-84 or syn b-PTH 1-34. Thus, the changes in HV - A glucose concentration difference and the $\mathrm{HV}$ - PV difference induced by b-PTH 1-84 are caused by an increase in hepatic glucose production, and they cannot be explained by changes in carbohydrate metabolism elsewhere in the splanchnic circulation.

Because the portal vein venous glucose concentration was $0-4 \mathrm{mg} / \mathrm{dl}$ less than arterial glucose concentration at any point, a minimal estimate of glucose addition 
TABLE II

Changes in Hepatic Vein Glucose Concentration after PTH Injections

\begin{tabular}{|c|c|c|c|c|c|c|c|c|c|c|c|}
\hline \multirow[b]{2}{*}{ Experiment } & \multicolumn{11}{|c|}{ Time $(\min )$} \\
\hline & -60 & -30 & -10 & 5 & 10 & 20 & 30 & 40 & 60 & 80 & 100 \\
\hline & \multicolumn{11}{|c|}{$m g / d l$} \\
\hline \multicolumn{12}{|c|}{$\begin{array}{l}\text { b-PTH } 1-84 \\
\quad \text { single injections }\end{array}$} \\
\hline 1 & 109 & 108 & 104 & 125 & 125 & 122 & 132 & 141 & 138 & 141 & 100 \\
\hline 2 & 106 & 107 & 102 & 108 & 106 & 107 & 109 & 109 & 133 & 132 & - \\
\hline 3 & 94 & 91 & 93 & 135 & 138 & 130 & 131 & 131 & 121 & 124 & 105 \\
\hline 4 & 97 & 103 & 101 & 107 & 114 & 110 & 115 & 115 & 114 & - & - \\
\hline 5 & 110 & 115 & 112 & 130 & 130 & 135 & 134 & 125 & 140 & - & - \\
\hline m & 103 & 105 & 102 & 121 & 123 & 121 & 124 & 124 & 129 & 132 & 103 \\
\hline SEM & 3 & 4 & 3 & 6 & 6 & 5 & 5 & 6 & 5 & & \\
\hline${ }^{*} P$ & & & & 0.05 & 0.02 & 0.02 & 0.02 & 0.02 & 0.01 & & \\
\hline \multicolumn{12}{|c|}{$\begin{array}{l}\text { syn b-PTH 1-34 } \\
\text { single injections }\end{array}$} \\
\hline 1 & 112 & 110 & 108 & 120 & 109 & 107 & 106 & 103 & 106 & 106 & - \\
\hline 2 & 117 & 107 & 107 & 117 & 117 & 115 & 107 & 107 & 105 & 105 & 98 \\
\hline 3 & 96 & 96 & 108 & 113 & 109 & 107 & 106 & 103 & 106 & 106 & - \\
\hline 4 & 109 & 111 & 109 & 110 & 114 & 110 & 118 & 112 & 110 & - & - \\
\hline 5 & 111 & 110 & 110 & 120 & 120 & 120 & 112 & 107 & 103 & - & - \\
\hline $\mathrm{m}$ & 109 & 107 & 108 & 116 & 114 & 112 & 110 & 106 & 106 & 106 & 98 \\
\hline SEM & 3 & 3 & 1 & 2 & 2 & 3 & 2 & 2 & 1 & & \\
\hline${ }^{*} P$ & & & & NS & NS & NS & NS & NS & NS & NS & NS \\
\hline
\end{tabular}

$\mathbf{m}=$ mean

* Unpaired Student's $t$ test (experiment periods vs. the -30 min control periods).

to the hepatic venous blood production can be reached by the product of total HPF and the hepatic vein minus arterial glucose concentration difference. Employing this calculation, the changes in glucose addition to the hepatic venous blood are shown in Table III for experiments with both b-PTH 1-84 and syn b-PTH 1-34. There were significant increases in glucose addition beginning with the first 10 min after each injection of bPTH 1-84. However, twice molar doses of syn b-PTH 1-34 had no demonstrable effect on hepatic glucose release.

Alanine uptake studies. To investigate the relationship between the hepatic gluconeogenic substrate, alanine, and the changes in hepatic glucose production shown above, the effect of PTH on estimated hepatic alanine uptake was examined. Hepatic alanine uptake calculated as described above in Methods was significantly increased by b-PTH 1-84 injections (Fig. 2). This increase in hepatic uptake was present at all intervals tested after injections (5-60 min). Mean \pm SEM arterial alanine levels were $234 \pm 5 \mu \mathrm{M}$ during control periods and $246 \pm 8 \mu \mathrm{M}$ in the plasma samples obtained after bolus b-PTH 1-84 injections. Portal alanine levels were $267 \pm 8 \mu \mathrm{M}$ in control periods and $278 \pm 5 \mu \mathrm{M}$ after
PTH administration. Hepatic vein alanine concentrations fell from $222 \pm 9 \mu \mathrm{M}$ control to $195 \pm 8 \mu \mathrm{M}$ after PTH. Thus, several factors may have contributed to the increase in hepatic alanine uptake observed after bPTH 1-84 administration. In depth evaluation of each of these factors (increased peripheral and/or splanchnic alanine delivery and increased hepatic alanine extraction) was beyond the scope of the present studies. As shown in Fig. 2, injections of syn b-PTH 1-34 were not followed by an increase in the hepatic uptake of alanine.

$\left[{ }^{14} \mathrm{C}\right]$ Alanine infusion studies. To further characterize the effect of b-PTH 1-84 on hepatic glucose release at more physiologic levels of the hormone, studies were undertaken in normal dogs injected with PTH so as to maintain serum levels in the hyperparathyroid range (1 $\mathrm{ng} / \mathrm{ml})$. These studies were also performed during infusion of alanine uniformly labeled with ${ }^{14} \mathrm{C}$. After $120 \mathrm{~min}$ of $\left[\mathrm{U}-{ }^{14} \mathrm{C}\right]$ alanine infusion, control blood samples were obtained from three dogs and b-PTH $1-84,1.2-2.5 \mathrm{ng} / \mathrm{kg}$ per min, was infused. After $60 \mathrm{~min}$ of PTH infusion with the alanine infusion continuing, experimental blood samples were obtained. The specific activity of $\left[{ }^{14} \mathrm{C}\right]$ alanine in arterial plasma during these experiments is shown in Fig. 3A. Arterial alanine 


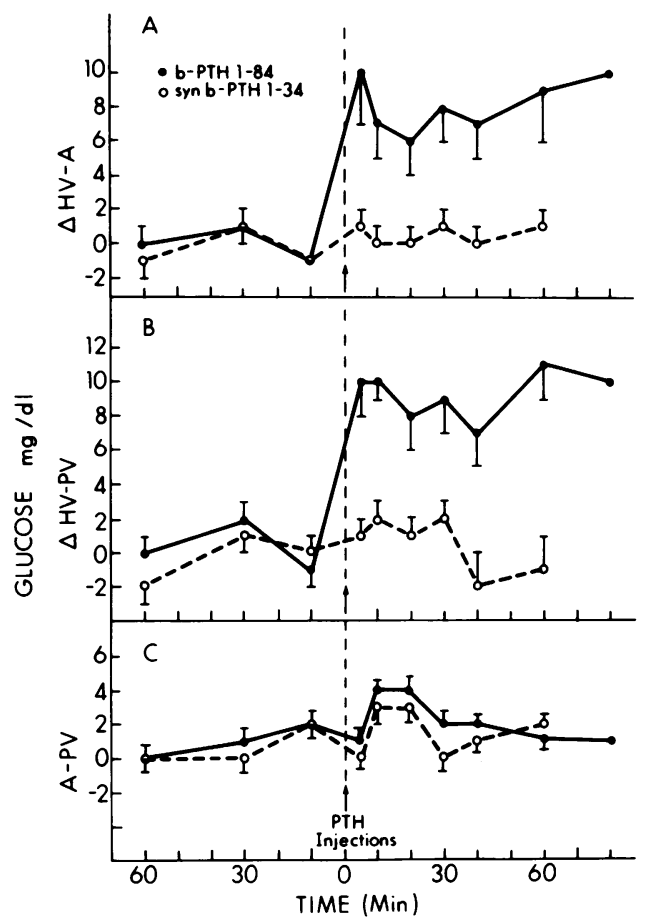

FIGURE 1 Effects of b-PTH 1-84 (O) and syn b-PTH 1-34 $(O)$ on $(A)$ the changes in the $H V-A$ difference $(\Delta H V-A)$ and (B) the changes in the HV - PV difference ( $\triangle H V-P V)$. Each point is the mean \pm SEM of the dogs listed in Table II as compared to the mean of all the control periods; (C) the A - PV difference. 80 -min points were obtained in only three dogs. All points from 5-60 min after b-PTH 1-84 injections different from control as assessed by nonpaired Student's $t$ test $(P<0.05>0.005)$.

concentrations were $253 \pm 12 \mu \mathrm{M}$ during control periods and $266 \pm 12 \mu \mathrm{M}$ during the b-PTH $1-84$ infusion. In Fig. 3B the effects of the b-PTH 1-84 infusions on hepatic venous glucose concentrations are portrayed. Hepatic venous glucose concentration rose steadily during the PTH infusion period. The incorporation of the ${ }^{14} \mathrm{C}$ label from alanine into glucose is shown as the hepatic $\left[{ }^{14} \mathrm{C}\right]$ glucose specific activity in Fig. 3C. PTH significantly increased the rate of ${ }^{14} \mathrm{C}$ incorporation into glucose. The slope of the $\left[{ }^{14} \mathrm{C}\right] \mathrm{glu}$ cose specific activity accumulation in the control period, $y=5.3(x)+152,(r=0.81)$, was significantly increased to $y=11.7(x)+167,(r=0.83)$ in the PTH infusion period. The increase in $\left[{ }^{14} \mathrm{C}\right]$ glucose specific activity suggested that one source of increased hepatic glucose release after PTH was enhanced gluconeogenesis with alanine as a substrate. Thus, an estimate of hepatic $\left[{ }^{14} \mathrm{C}\right]$ alanine uptake was made as described above in Methods. b-PTH 1-84 infusions increased the estimated alanine uptake as shown in Fig. 3D from a mean of $87 \times 10^{3} \mathrm{dpm} / \mathrm{min}$ per $\mathrm{kg}$ to $213 \times 10^{3} \mathrm{dpm} / \mathrm{min}$ per $\mathrm{kg}$. Because arterial and portal $\left[{ }^{14} \mathrm{C}\right]$ alanine levels were kept constant by the infusion technique, the increase in $\left[{ }^{14} \mathrm{C}\right]$ alanine uptake by the liver shown in Fig. 3 is caused by a decrease in the $\left[{ }^{14} \mathrm{C}\right]$ alanine exiting from the liver. Thus, the difficulty imposed by having to estimate alanine delivery for the calculation of chemical alanine uptake is canceled and the observation of increased alanine uptake is strengthened. PTH levels were constant during the experimental period ranging from 0.8 to $1.2 \mathrm{ng} / \mathrm{ml}$ (mean $1.0 \pm 0.18 \mathrm{SD}$ ) of immunoreactive $\mathrm{PTH}$ determined with a $\mathrm{NH}_{2}$-terminal PTH radioimmunoassay (1). The studies during syn b-PTH 1-34 administration again revealed no effect on hepatic alanine uptake.

Changes in plasma glucagon and insulin. Because changes in glucose concentrations would be expected to alter glucagon and insulin release, the plasma levels of these hormones were followed during the course of these studies. As shown on Fig. 4A, there was a tendency for mean plasma glucagon to decrease after the injection of b-PTH 1-84. As shown in Fig. 4B, there was an increase in arterial insulin levels after b-PTH 1-84 administration. Mean plasma insulin levels were significantly increased at 10 and $60 \mathrm{~min}$ after PTH as compared to base-line periods in the groups of dogs receiving b-PTH 1-84.

\section{DISCUSSION}

We have reported (1) a specific uptake and degradation of b-PTH 1-84 by the canine liver in vivo. We also found no demonstrable hepatic uptake of syn b-PTH 1-34 or COOH-terminal PTH fragments. The present studies demonstrate biologic effects of b-PTH 1-84 on the canine liver. b-PTH 1-84 administration increased glucose release from the liver and stimulated gluconeogenesis from alanine. On the other hand, administration of syn b-PTH 1-34 had no demonstrable effect on glucose release. Thus, the uptake of b-PTH 1-84 by the liver was correlated with a specific biologic effect, and absence of uptake of syn b-PTH 1-34 with absence of such an effect. These studies suggest that hepatic PTH uptake is related to specific biologic effects of the hormone, and that the liver is more than just a site of degradative uptake of PTH.

PTH hormone has been shown to increase adenylate cyclase activity and $3^{\prime} 5^{\prime}$-cyclic AMP concentrations in rat liver cells and homogenates in vitro $(4,5)$. In addition, PTH stimulated gluconeogenesis, glycogenolysis, and urea production in isolated rat liver cells. Thus, in vitro studies suggested that the liver might represent a target organ of PTH biologic activity. The doses of PTH employed to demonstrate the above-mentioned effects $(1-0.1 \mu \mathrm{M})$ were clearly pharmacologic but this was also the case in studies related to the effects of 
TABLE III

Changes in Glucose Addition to the Hepatic Venous Blood

\begin{tabular}{|c|c|c|c|c|c|c|c|c|c|c|c|}
\hline \multirow[b]{2}{*}{ Experiment } & \multicolumn{11}{|c|}{ Time (min) } \\
\hline & -60 & -30 & -10 & 5 & 10 & 20 & 30 & 40 & 60 & 80 & 100 \\
\hline & \multicolumn{11}{|c|}{ mg/min/kg } \\
\hline \multicolumn{12}{|c|}{$\begin{array}{l}\text { b-PTH } 1-84 \\
\quad \text { single injections }\end{array}$} \\
\hline 1 & 5 & 25 & 5 & 42 & 69 & 48 & 101 & 69 & 64 & 48 & 45 \\
\hline 2 & 27 & 27 & 23 & 46 & 53 & 68 & 42 & 49 & 57 & 110 & - \\
\hline 3 & 45 & 45 & 0 & 125 & 80 & 100 & 50 & 25 & 50 & 5 & 5 \\
\hline 4 & 0 & 6 & 0 & 11 & 44 & 50 & 44 & 66 & 50 & - & - \\
\hline 5 & 45 & 52 & 70 & 116 & 87 & 75 & 99 & 100 & 104 & - & - \\
\hline $\mathrm{m}$ & 24 & 31 & 20 & 68 & 67 & 68 & 67 & 62 & 65 & 54 & - \\
\hline SEM & 9 & 8 & 13 & 22 & 8 & 9 & 13 & 12 & 10 & - & - \\
\hline$P^{*}$ & & & & NS & 0.02 & 0.02 & 0.05 & NS & 0.05 & - & - \\
\hline \multicolumn{12}{|c|}{$\begin{array}{l}\text { syn b-PTH 1-34 } \\
\text { single injections }\end{array}$} \\
\hline 1 & 0 & 31 & 0 & 31 & 31 & 57 & 10 & 5 & 36 & 15 & - \\
\hline 2 & 49 & 24 & 37 & 12 & 31 & 36 & 67 & 43 & 55 & - & - \\
\hline 3 & 0 & 47 & 27 & 60 & 54 & 54 & 34 & 34 & 54 & 34 & - \\
\hline 4 & 29 & 78 & 29 & 24 & 34 & 34 & 53 & 45 & 39 & - & - \\
\hline 5 & 25 & 20 & 32 & 0 & 12 & - & 24 & 40 & 8 & - & - \\
\hline m & 21 & 40 & 25 & 23 & 32 & 45 & 37 & 33 & 38 & - & - \\
\hline SEM & 9 & 10 & 6 & 10 & 7 & 5 & 10 & 7 & 8 & - & - \\
\hline$P \ddagger$ & & & & NS & NS & NS & NS & NS & NS & - & - \\
\hline
\end{tabular}

m, mean.

* Nonpaired $t$ test; each experimental period vs. control period with highest mean glucose addition.

f Nonpaired $t$ test; each experimental period vs. control period with lowest mean glucose addition.

PTH on gluconeogenesis and cyclic AMP production by renal tubules and slices $(2,3,17,18)$. The arterial blood levels of immunoreactive PTH (1-2 $\mathrm{nM}$ in a $\mathrm{COOH}$-terminal radioimmunoassay) attained in the first 1-5 min after the bolus injections of b-PTH 1-84

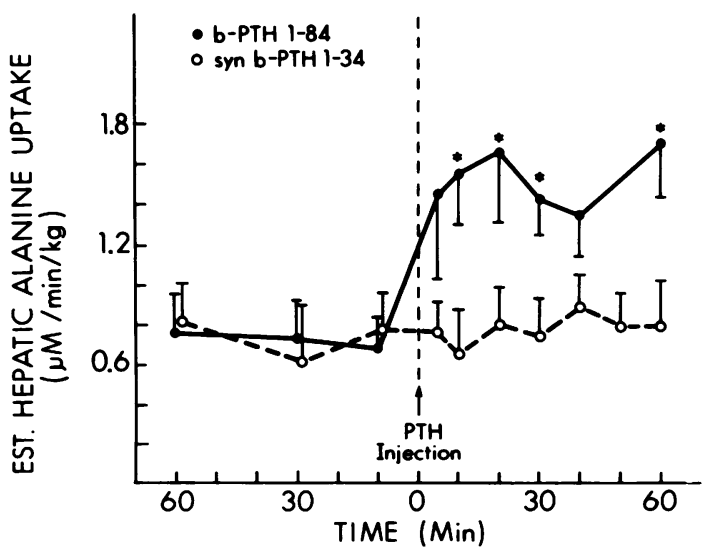

FIGURE 2 Estimated (Est.) hepatic alanine uptake calculated as discussed in Methods. Asterisk, points different from control as assessed by nonpaired Student's $t$ test $(P<0.05>0.01)$. employed in the present studies were also pharmacologic $(18,19)$. However, the PTH levels obtained during the constant infusion of b-PTH 1-84 (alanine incorporation studies) were in the range seen in dogs with nutritionally induced hyperparathyroidism when fed a high phosphorus-low calcium diet or in uremic dogs when the PTH levels are determined using a radioimmunoassay specific for the amino terminus of PTH. ${ }^{2}$ The levels of PTH obtained in these experiments are, therefore, in the physiologic range and clearly demonstrate a biologic effect of PTH on hepatic carbohydrate metabolism in vivo.

The studies performed during infusion of $\left[{ }^{14} \mathrm{C}\right]$ alanine using PTH administration rates comparable to production rates seen in states of hyperparathyroidsm not only demonstrate that the PTH effect on hepatic glucose production is physiologic, but also confirm the studies using only chemical glucose determinations. There was a significant stimulatory affect of PTH on the rate of ${ }^{14} \mathrm{C}$ appearance in glucose, and an increase in the estimated hepatic uptake of $\left[{ }^{14} \mathrm{C}\right]$ alanine. Thus, PTH

\footnotetext{
${ }^{2}$ Hruska, K., and E. Slatopolsky. Unpublished observations.
} 


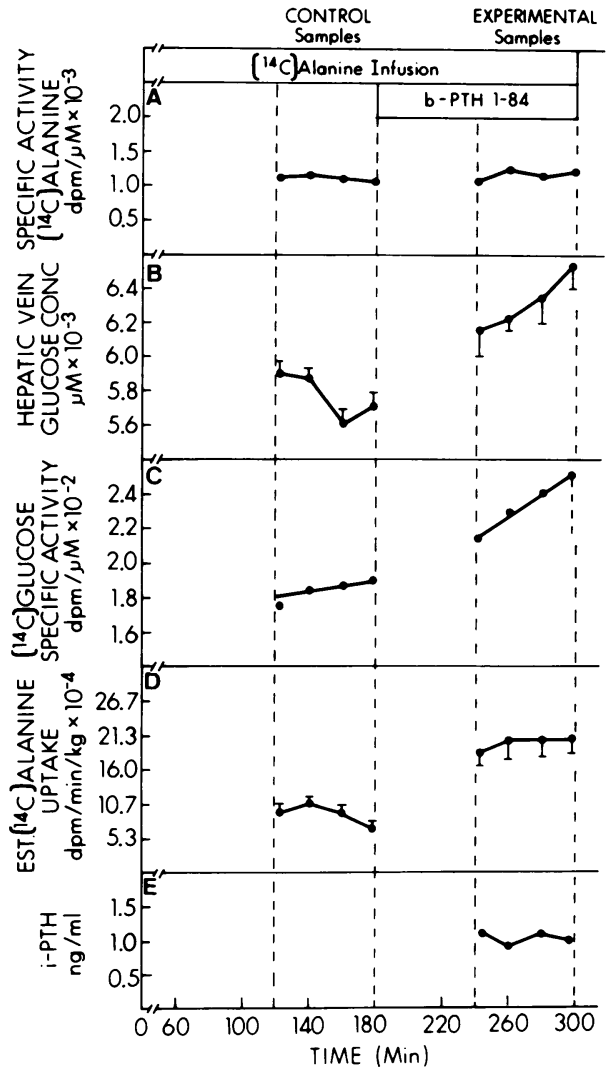

FIgUre 3 Studies in three dogs during constant infusion of $\left[{ }^{14} \mathrm{C}\right]$ alanine, and constant infusion of b-PTH 1-84 beginning after collection of four control samples. Control samples collected between $120-180 \mathrm{~min}$ of $\left[{ }^{14} \mathrm{C}\right]$ alanine infusion and experimental samples from $240-300 \mathrm{~min}$ of $\left[{ }^{14} \mathrm{C}\right]$ alanine infusion. Mean hepatic vein $\left[{ }^{14} \mathrm{C}\right]$ glucose specific activity rose according to a line $y=5.34(x)+152,(r=0.81)$ during the control period as compared to $y=11.66(x)+167,(r=0.83)$ in the experimental periods. The slope of the regression line was significantly greater in the experimental period as compared to the control (>95\% confidence limit). Est. hepatic $\left[{ }^{14} \mathrm{C}\right]$ alanine uptake (dpm) was significantly greater during each experimental determination compared to the mean control uptake as assessed by nonpaired Student's $t$ test $(P<0.05)$. Immunoreactive PTH (i-PTH) levels were undetectable during control periods and $0.9-1.1 \mathrm{ng} / \mathrm{ml}$ in the experimental periods.

clearly stimulated hepatic gluconeogenesis with alanine as a substrate.

Although PTH may not be an important regulator of hepatic glucose homeostasis under normal conditions, it may have important effects in hyperparathyroid states. Glucose intolerance has been reported in primary hyperparathyroidism $(20,21)$ and in chronic renal failure (22). The role of PTH in the altered carbohydrate metabolism observed in these states has not been examined.

The absence of an effect of syn b-PTH 1-34 on hepatic glucose production in the present studies is in contrast to previous studies performed in isolated rat liver hepatocytes and homogenates (5). In these studies

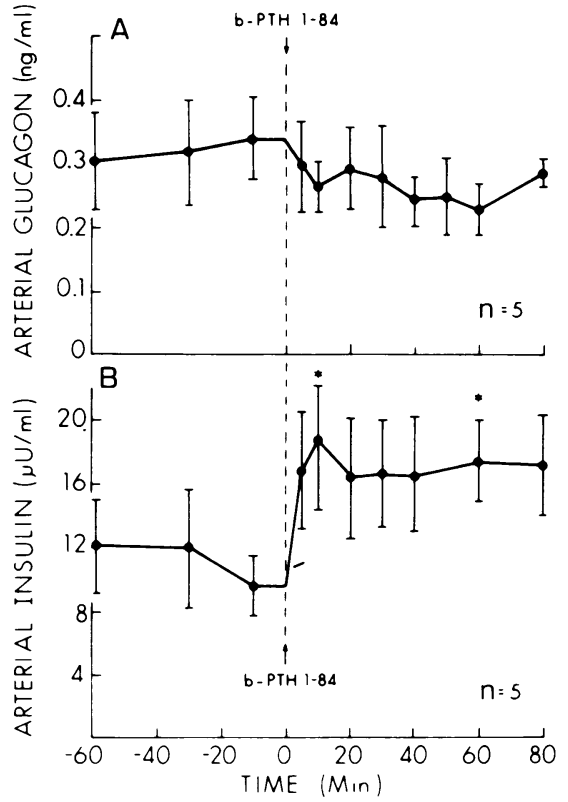

Figure 4 Mean \pm SEM arterial glucagon and insulin levels after b-PTH 1-84 injections. There was a tendency for arterial glucagon to fall. The rises in arterial insulin were significantly different at 10 and $60 \mathrm{~min}$ after injection $\left({ }^{*}, P<0.05\right)$.

syn b-PTH 1-34 stimulated adenylate cyclase activity and both glycogenolysis and gluconeogenesis to a degree equal to the effects seen with b-PTH 1-84. Obvious differences between these previous studies and those reported here may explain the discrepant results obtained. These differences include a different species of animal studied and the difficulty of comparing in vitro results to in vivo studies. However, no definite explanation for the observed differences in response to syn b-PTH 1-34 was apparent during the present studies.

The mechanisms responsible for the increase in hepatic glucose production after b-PTH 1-84 injections appeared to involve both increased glycogenolysis and gluconeogenesis judging from the rapidity of the increase in hepatic venous glucose concentration and the duration of the PTH effect for 80 min after injection. PTH has been shown in vitro to affect both of these processes responsible for increasing hepatic glucose production $(5,6)$. Moxley et al. (5) also demonstrated gluconeogenesis from $\left[\mathrm{U}-{ }^{14} \mathrm{C}\right]$ alanine with the label appearing in newly formed $\left[{ }^{14} \mathrm{C}\right]$ glucose. The results of the present study demonstrate increased estimated hepatic uptake of alanine extending from $10-60 \mathrm{~min}$ after bolus injections of b-PTH 1-84. These results suggest that alanine was one of the substrates involved in the increased gluconeogenesis observed after bPTH administration. The mechanism of increased alanine uptake involved both increased delivery from arterial and portal venous sources in individual dogs and an increase in hepatic alanine extraction. The 
studies during $\left[{ }^{14} \mathrm{C}\right]$ alanine infusion suggest that increased hepatic extraction of alanine was an important factor in the increased hepatic alanine uptake. These studies do not necessarily confirm that PTH stimulates alanine release from striated muscle as suggested by Garber (23) in vitro, because a consistent rise in arterial alanine levels was not observed in all dogs.

The observed changes in arterial glucagon and insulin levels after b-PTH 1-84 injections are those to be expected after a glucose load. Thus, these results both confirm the presence of increased glucose production after b-PTH 1-84 and suggest that the changes in the plasma levels of insulin and glucagon were secondary and did not contribute to the observed increased hepatic glucose production.

In conclusion, these studies demonstrate an effect of intact PTH on hepatic glucose production in vivo. They extend our previous report, which demonstrated specificity of canine hepatic uptake for the intact form of PTH. The demonstration that syn b-PTH 1-34 failed to stimulate hepatic glucose production and was not taken up by the liver is consistent with a close correlation between uptake and the effects of PTH on glucose release. It is suggested that future studies of hepatic PTH metabolism consider the biologic actions of PTH on the liver and not focus solely on this organ as a peptide degradation site.

\section{ACKNOWLEDGMENTS}

The authors would like to express their appreciation to $\mathrm{Mr}$. Henry Burke for his technical assistance.

This work was supported by U. S. Public Health Service National Institute of Arthritis, Metabolism, and Digestive Diseases grants AM-07126, AM-09976, and AM-20579, and by a grant from the St. Louis Diabetes Association.

\section{REFERENCES}

1. Martin, K., K. Hruska, A. Greenwalt, S. Klahr, and E. Slatopolsky. 1976. Selective uptake of intact parathyroid hormone by the liver. Differences between hepatic and renal uptake. J. Clin. Invest. 58: 781-788.

2. Kurokawa, K., T. Ohno, and H. Rasmussen. 1973. Ionic control of renal gluconeogenesis. II. The effect on $\mathrm{Ca}^{2+}$ and $\mathrm{H}^{+}$upon the response to parathyroid hormone and cyclic AMP. Biochem. Biophys. Acta. 313: 32-41.

3. Guder, W. G., and O. H. Wieland. 1972. Metabolism of isolated kidney tubules. Additive effects of parathyroid hormone and free-fatty acids on renal gluconeogenesis. Eur. J. Biochem. 31: 69-79.

4. Canterbury, J. M., G. Levy, E. Ruiz, and E. Reiss. 1974. Parathyroid hormone activation of adenylate cyclase in liver. Proc. Soc. Exp. Biol. Med. 147: 366-370.

5. Moxley, M. A., N. H. Bell, S. R. Wagle, D. O. Allen, and J. Ashmore. 1974. Parathyroid hormone stimulation of glucose and urea production in isolated liver cells. Am.J. Physiol. 227: 1058-1061.

6. Hems, D. A., C. S. Harmon, and P. D. Whitton. 1975. Inhibition by parathyroid hormone of glycogen synthesis in the perfused liver. FEBS (Fed. Eur. Biochem. Soc.) Lett. 58: 167-169.

7. Shoemaker, W. C., W. F. Walker, T. B. Van Italie, and
F. D. Moore. 1959. A method for simultaneous catheterization of the major hepatic vessels in a chronic canine preparation. Am. J. Physiol. 196: 311-314.

8. Seldinger, S. I. 1953. Catheter replacement of the needle in percutaneous arteriography. A new technique. Acta Radiol. 39: 368-376.

9. Ketterer, S. G., B. D. Wiegand, and E. Rappaport. 1960. Hepatic uptake and biliary excretion of indocyanine green and its use in estimation of hepatic blood flow in dogs. Am. J. Physiol. 199: 481-484.

10. Nagata, N. and H. Rasmussen. 1970. Renal gluconeogenesis: effects of $\mathrm{Ca}^{2+}$ and $\mathrm{H}^{+}$. Biochem. Biophys. Acta. 215: 1-16.

11. Steiner, A. L., A. Pagliara, L. Chase, and D. M. Kipnis. 1972. Radioimmunoassay for cyclic nucleotides: II. Adenosine $3^{\prime} 5^{\prime}$-monophosphate and quanosine $3^{\prime} 5^{\prime}$ monophosphate in mammalian tissues and body fluids. J. Biol. Chem. 247: 1114-1124.

12. Hales, C. N., and M. L. Parker. 1963. Immunoassay of insulin with insulin antibody precipitate. Biochem. J. 88: $137-146$.

13. Leichter, S. G., A. S. Pagliara, M. H. Greider, S. Phol, J. Rosai, and D. M. Kipnis. 1975. Uncontrolled diabetes mellitus and hyperglucagonemia associated with an islet cell carcinoma. Am. J. Med. 58: 285-293.

14. Garber, A. J., P. E. Cryer, J. V. Santiago, M. W. Haymond, A. S. Pagliara, and D. M. Kipnis. 1976. The role of adrenergic mechanisms in the substrate and hormonal response to insulin induced hypoglycemia in man. J. Clin. Invest. 58: 7-15.

15. Karl, I. E., A. S. Pagliara, and D. M. Kipnis. 1972. A microfluorometric enzymatic assay for the determination of alanine and pyruvate in plasma and tissues. J. Lab. Clin. Med. 80: 434-441.

16. Lowry, O. H., and J. V. Passonneau. 1972. A flexible system of enzymatic analysis. Academic Press, Inc., New York, 149-150.

17. Charbon, G. A., and P. F. Hulstaert. 1974. Augmentation of arterial hepatic and renal flow by extracted and synthetic parathyroid hormone. Endocrinology. 95: 621-626.

18. Parsons, J. A., B. Rafferty, D. Gray, B. Reit, J. M. Zanelli, H. T. Keutmann, E. W. Tregear, E. N. Callahan, and J. T. Potts, Jr. 1975. Pharmacology of parathyroid hormone and some of its fragments and analogues. In Calcium Regulating Hormones. Proceedings of the Fifth Parathyroid Conference. R. V. Talmage, M. Owen, and J. A. Parsons, editors. Excerpta Medica, Amsterdam. 33-39.

19. Hruska, K. A., R. Kopelman, W. E. Rutherford, S. Klahr, and E. Slatopolsky. 1975. Metabolism of immunoreactive parathyroid hormone in the dog. The role of the kidney and the effects of chronic renal disease. J. Clin. Invest. 56: $39-48$.

20. Ginsberg, H., J. M. Olefsky, and G. M. Reaven. 1975. Evaluation of insulin resistance in patients with primary hyperparathyroidism (38665). Proceedings of the Society for Experimental Biology and Medicine. 148: 942-945.

21. Hakjoong, K., R. K. Kalkhoff, N. V. Costrini, J. M. Cerletty, and M. Jacobson. 1971. Plasma insulin disturbances in primary hyperparathyroidism. J. Clin. Invest. 50: 25962605.

22. DeFronzo, R. A., R. Andres, P. Edgar, and W. G. Walker. 1973. Carbohydrate metabolism in uremia: a review. Medicine. 62: 469-481.

23. Garber, A. J. 1978. Skeletal muscle protein and amino acid metabolism in experimental chronic uremia in the rat. Accelerated alanine and glutamine formation and release. J. Clin. Invest. 62: 623-632. 